\title{
A Study on the Volatility of the Bangladesh Stock Market - Based on GARCH Type Models
}

\section{Bhowmik RONI*}

Academy of Mathematics and Systems Science, Chinese Academy of Sciences, Beijing 100190, China; University of Chinese Academy of Sciences, Beijing 100190, China; Daffodil International University,

Bangladesh

E-mail:roni@amss.ac.cn; roni@mails.ucas.ac.cn

\section{Chao WU}

Academy of Mathematics and Systems Science, Chinese Academy of Sciences, Beijing 100190, China; University of Chinese Academy of Sciences, Beijing 100190, China

E-mail: wuchao12@mails.ucas.ac.cn

Roy Kumar JEWEL

Jatiya Kabi Kazi Nazrul Islam University, Bangladesh

E-mail: jewelroy91@gmail.com

\section{Shouyang WANG}

Academy of Mathematics and Systems Science, Chinese Academy of Sciences, Beijing 100190, China; University of Chinese Academy of Sciences, Beijing 100190, China

E-mail: sywang@amss.ac.cn

\begin{abstract}
The generalized autoregressive conditional heteroskedasticity (GARCH) type models are used to investigate the volatility of Bangladesh stock market. The findings of the study demonstrate that the index volatility characteristics changes over time. The article shows that the data are divided into three sub-periods: pre crisis, crisis, and post crisis. Accordingly, the results of the findings indicate changes in the GARCH-type models parameter, risk premium and persistence of volatility in different periods. A significant "low-yield associated with high-risk" phenomenon is detected in the crisis period and the "leverage effect" occurs in each periods. The investors are irrational which is based on assumption of risk and return characteristics of assets. Consequently, the market is not as mature as developed market. It is found in the article that the threshold generalized autoregressive conditional heteroskedasticity (TGARCH) model is more accurate for the model accuracy. Additionally, statistic error measurements indicate that GARCH model is more efficient than others and it has also more forecasting ability.
\end{abstract}

Keywords Bangladesh stock market; volatility forecasting; GARCH type models; leverage effect

Received February 7, 2017, accepted May 25, 2017

Supported by the National Natural Science Foundation of China (71490725) and the Humanities and Social Science Project of Ministry of Education (14YJA630015)

*Corresponding author 


\section{Introduction}

Economics editor $^{[1]}$ from the renowned daily newspaper, upholds that developing countries like Bangladesh and Mexico will be the same as BRICS plateau and they have a bright future to overtake the western countries within the year 2050. As a South Asian country, Bangladesh economically is on target to have grown of nearly $7 \%$ in 2017 and it would be the highest rate at end of the year in South Asia. The expected economic growth rate of Bangladesh would be relatively better than the entire Pacific countries according to the International Monetary Fund. For the development countries, monetary and financial sectors participate as a vital component by mobilizing resources. Strategically, the stock market is an important part of financial markets and it is considered as the blood of the economy. Stock market may also have a major effect on the development of economy in Bangladesh. The effectiveness of most productive stock markets comes from mobilizing resources which are actually well-known.

Volatility is one of the existing features in financial markets. Now-a-days, global markets have become more volatile and this phenomenon has generated growing concentration for researchers, academicians, and portfolio managers in the study of market volatility. Volatility is involved in the prices of the stock index, which has a negative impact on particular individual income as well as overall health of the country's economy. The stock market volatility is mainly embodied in the possibility of future price deviation from the expected value. It can be defined in simple terms as the frequency and severity of the fluctuations in the market price. From the observation of Oseni and Nwosa ${ }^{[2]}$, it can be regarded that there is a greater chance of volatility which is based on the fluctuation of share price in the stock market.

Over the past two decades, due to overvaluing and overheating created by gamblers, the Bangladesh stock market has to face two big bubbles leading to a session of volatility. First time in 1996, stock market is crashed because of speculative bubble, investigated by Hasan, et al. ${ }^{[3]}$. Islam and Zaman ${ }^{[4]}$ explain that the end of 1995 DSEX is 834 points but within a few months DSEX price index raised 337\%. DSE experiences a dramatic change and pushes the DSEX price index to 3648.7 points on November 5, 1996. Within a day, the DSEX index has fallen over 233 points on 6, November. As a result the DSEX price index is dropped to its lowest point after the bubble burst and falls to 957 points in April, 1997.

In the recent crash DSE is found after the global financial crisis. DSE in which painful

memories of 2011 bubble, Hasan, et al. ${ }^{[3]}$ finds out the cause of crash which is an asset pricing bubble. DSE Index is increased to 4000 points for the first time in November, 2009; but from such a low index level, DSEX crosses 8500 points within mid-2010. Soon after, share price has crashed and DSEX is dropped sharply about 3400 points. As a result, the index chart is increased more than $22 \%$ in a day on 16, November 2009 found out by Ahmed ${ }^{[5]}$. By the

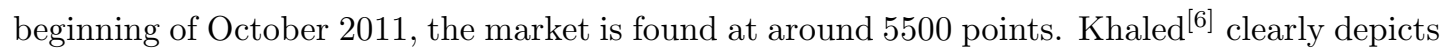
that as a result of the sharp fall of index, the Central Bank of Bangladesh instructs its sister investment concern to stop giving loans to their clients to buy market shares and has directed to recover their capital investments in some way. As a result, the banks has to sell (so called "force sell") their client's shares without any prior notice. As a counter reaction, other share-holders sell their shares at a minimum loss.

It is argued worldwide whether the stock market volatility is higher or not in the 'bull' 
market than the 'bear' market. This kind of fall is deemed 'normal' for every stock market which is overvalued, initiating the big bubble. From 2009-2011, the Bangladesh stock market is categorically overvalued. Khaled ${ }^{[6]}$ mentioned in his report that the market is manipulated by some distinct gamblers (group of manipulators including key auditors, issuers, issue-managers, brokers, individual investors, and stakeholders) who remain in the shadows. To find out whether the Bangladesh stock market is overvalued or not, this study has compared Market Capitalization (MC) to Gross Domestic Product (GDP) ratio to discover the economic status. As it is known that GDP values are used as a proxy for economic growth and MC ratio is used as a proxy for stock market development, MC to GDP ratio tends to be higher in developed countries and lower in developing countries.

Few years ago, world famous investor Warren Buffett introduces a technique, MC to GDP ratio, which defines that if the relationship tends to be between $70 \% \sim 80 \%$, buying stocks is likely to work very well. If the ratio approaches $200 \%$, then the market is overvalued. Table 1 shows that MC to GDP ratio contributes $4.8 \%$ in the $2001-02$ period, $38.9 \%$ in the $2009-10$ period, and $21.5 \%$ in the $2014-15$ period. It indicates that the Bangladesh stock market is developing too fast and has some unpredictable volatility. However, it's understandable that from the year of 2009 to 2011 market is an overvalued and unusual in the situation of natural trend of Bangladesh stock market (Table 1).

Table 1 Size of the Bangladesh's stock market

\begin{tabular}{llllllll}
\hline Year & $\begin{array}{l}\text { GDP } \\
\text { (Billion BDT) }\end{array}$ & $\begin{array}{l}\text { MC } \\
\text { (Billion BDT) }\end{array}$ & $\begin{array}{l}\text { MC to } \\
\text { GDP }\end{array}$ & Year & $\begin{array}{l}\text { GDP } \\
\text { (Billion BDT) }\end{array}$ & $\begin{array}{l}\text { MC } \\
\text { (Billion BDT) }\end{array}$ & $\begin{array}{l}\text { MC to } \\
\text { GDP }\end{array}$ \\
\hline $2001-02$ & 2732.0 & 131.7 & 0.048 & $2008-09$ & 6155.5 & 1241.3 & 0.202 \\
$2002-03$ & 3005.8 & 182.8 & 0.061 & $2009-10$ & 6943.2 & 2700.7 & 0.389 \\
$2003-04$ & 3329.7 & 439.9 & 0.132 & $2010-11$ & 7967.0 & 2853.9 & 0.358 \\
$2004-05$ & 3707.0 & 453.0 & 0.122 & $2011-12$ & 10552.0 & 2491.6 & 0.236 \\
$2005-06$ & 4157.2 & 420.8 & 0.101 & $2012-13$ & 11989.2 & 2530.2 & 0.211 \\
$2006-07$ & 4724.9 & 491.7 & 0.104 & $2013-14$ & 13436.7 & 2943.2 & 0.219 \\
$2007-08$ & 5458.2 & 931.0 & 0.171 & $2014-15$ & 15136 & 3247.3 & 0.215 \\
\hline
\end{tabular}

Source: Authors calculation from various issues of Bangladesh Bank Data source, Bangladesh Economic Review, Statistical Year Book of Bangladesh, DSE (main board) and SEC (annual report review).

DSE is important for Bangladesh economic development because it works as a system for resource re-allocation among the economy of different sectors. Bangladesh has gone through financial sector reforms during the last decade. Especially after 2011, when the stock markets of Bangladesh bubbled. After 2010, Bangladesh stock markets have had noticeable improvements in terms of policy and trading methods, as Bangladesh Security \& Exchange Commissions (BSEC) have extended facilities to centrally controlled and suspended transactions of DSE to ensure the security of the investors and prevent such downfall of market share price in the future. Any vital, structural, and strategy changes that are regularly highlighted by both academics and investors of national or international which are constantly updated by DSE. 
Without the above mentioned two big bubbles, generally Bangladesh stock markets have lower volatility. Nevertheless volatility is inevitable for the developed and developing stock markets. It is also called the spirit of the market ${ }^{[7]}$. Due to this purpose, stock market's volatility is one of the most important features of today's financial markets. The forecast of volatility has several applications in the financial field like value at risk (VaR) and research of forecasting performance of a variety of volatility models which are already been done in the markets of developed and developing countries.

However, stock markets of emerging Bangladesh have not been thoroughly studied yet. This paper examines volatility and stock return of DSEX where the researchers are motivated by market history and emerging market prospects. The paper is significant in the following respects. First, the current study is employing a larger data set and data are divided into three sub-periods. Second, the study examines the both symmetric and asymmetric GARCH type models. Third, it is to investigate the model forecasting performance by two different methods, such as error statistic measurements and model accuracy.

The rest of the paper is structured as follows: (I) The background and research motivation; (II) Review of the related literature about emerging stock market volatility and different GARCH type models; (III) Provides details on the data set and outlines the basic analysis; (IV) Presents the GARCH methodology for the data analysis; (V) Works from the discussion of the empirical results and forecasting accuracy comparison of models in different periods; and (VII) draws the conclusion of this findings.

\section{$2 \quad$ Literature Review}

Researchers have investigated about stock market volatility for long periods. However, market participants are mostly concerned with volatility and equity returns. There are several reasons why academics and practitioners have found interest in conducting research in the sector of modeling and forecasting the volatility of stock markets. Among all the basic reason, it is an exceptional fertile sector for research in the category of finance and economics. Moreover, it is a well-known fact that stock markets play the most prominent role in a country's modern economic development. The nature of stock market volatility gives us some important implications for economic forecasters, investors, and researchers.

Volatility is mainly related to investment markets. It is referring to fluctuation or movement in the price of particular stock or index major over some period of time. Volatility is the amount of price ups and downs movements a security experiences over a given period of time. In higher volatility, a dramatic change occurs in the security of price that can be transformed to the other direction within a short period of time. According to Schwert ${ }^{[8]}$, volatility increases immediately following stock prices going down. It will increase especially during recessions as well as approximately significant financial crises. It generates atmosphere of the incertitude and for this reason, it hampers effective investment. Black ${ }^{[9]}$ highlighted that while bad rumors are found, market price is shrunk immediately, and the good rumors push the market price to boost on the impact of the index. As a consequence, leverage effect associate with volatility returns in stock markets.

Ever since the second volatility event in 2009, DSE index is found in an upward direction and 
most of the investors have a strong feeling that this would keep up regardless of the country's present economy. However, the situation is not sustainable for a very long time. Volatility can help making money but it can be risky for the first time investor. It is found advantageous when skilled investors work on this volatility and take the advantages by understanding the market value through buying more of what is cheaper and selling more of what is expensive. Gencay and Selcuk ${ }^{[10]}$ and Llaudes, et al. ${ }^{[11]}$ pointed out that emerging stock markets economies are more subject matter to regime changes within a short time. Therefore, it is quite easy to invest for experienced investors in emerging markets.

As a test for the vulnerability of stock markets, researchers often depend on market estimates of volatility. More recently, Baker, et al. ${ }^{[12]}$, Beer, et al. ${ }^{[13]}$ and Li, et al. ${ }^{[14]}$ explained that investor's sentiment is also vulnerable due to the trends of stock market ups and downs. Therefore, volatility is considered as the vital factor of the stock market improvements offering an essential input for the purpose of portfolio management, option pricing and stock market rules and regulations. Moreover, volatility of the trends promotes long extension of investor's sentiment and has been troubling Bangladeshi investors. Research results prove that the stock returns in performance for a certain time period have relatively small fluctuations, and vice versa. During the period 2009 to 2010, the existence of "rush for the thick tail, small but persistent memory, and volatility clustering" phenomenon is found in Bangladesh stock market.

Engle ${ }^{[15]}$ proposed autoregressive conditional heteroscedasticity $(\mathrm{ARCH})$ model, which becomes an important model for analyzing time series data. Even so, it is difficult to forecast accurately in the financial applications and takes more time. Consequently, Bollerslev ${ }^{[16]}$ developed a model to predict financial time series which are easy to estimate and even in its simplest form, has proven surprisingly successful in predicting conditional variances. The generalized ARCH model is often known as GARCH. GARCH model has multiple entries with multiple applications. Conditional variance of the model is not only related to the pre-disturbance, but also with the relevant pre-conditional variance. GARCH equation assumes that there are mean and variance of the equation. GARCH model of non-constant volatility can be used to describe volatility of conditional variances time variability. This means GARCH model is unconditionally homoscedastic but conditionally heteroscedastic.

In response to this phenomenon, Nelson ${ }^{[17]}$, Glosten, et al. ${ }^{[8]}$, and Zakoian ${ }^{[19]}$, revised the traditional ARCH model and proposed two nonsymmetrical models. One is the threshold generalized autoregressive conditional heteroscedastic (TGARCH) model, and another is exponential generalized autoregressive conditional heteroscedastic (EGARCH) model. Gencay and Selcuk ${ }^{[10]}$ explained GARCH parameters which has the ability to explain the condition of persistency of the volatility. Nor, et al. ${ }^{[20]}$, Ezzat ${ }^{[21]}$, and Ehlert, et al. ${ }^{[22]}$, further noticed that remarkable developments can be accomplished by using a GARCH model in the conditional variance.

One of the disgracefully tricky tasks for a researcher is volatility forecasting; since, there is no single standard method and model for analysis of volatility. Different researchers suggest and follow various models including error statistics to rank volatility forecasting models. Brailsford and Faff ${ }^{[23]}$ explained that GARCH of Glosten, Jagannathan, and Runkle (GJR-GARCH) is the best model for volatility forecasting of the daily stock market of Australia. Moreover, 
it is confirmed that GARCH type models are suitable for performing stock return volatility for developed and emerging markets. Abdalla and Winker ${ }^{[24]}$ found out that GARCH type models perform best in emerging market. Poon and Granger ${ }^{[25]}$ noticed that EGARCH and GJR-GARCH have much better than GARCH model.

Allen, et al. ${ }^{[26]}$ found out that GARCH models can be successfully applied to calculate approximately VaR. Hai-nan and Wei ${ }^{[27]}$ have found that GJR model are more effective on forecasting and they can be applied with high frequency data. Only GARCH $(1,1)$ is effectively taken over by the other opponent model, as shown by Awartani and Corradi ${ }^{[28]}$. Ederington and Guan ${ }^{[29]}$ explained that in emerging stock markets, $\operatorname{GARCH}(1,1)$ model outperforms for volatility forecasting. On the one hand, Liu, et al. ${ }^{[30]}$ indicated that the asymmetric EGARCH model produces the best performance for volatility forecasting than its alternatives in developed markets. Ezzat ${ }^{[21]}$ investigated that the risk return parameter is positive and statistically significant while EGARCH and TGARCH models are not significant for asymmetry in stock returns. The explanation of Alberg, et al. ${ }^{[31]}$ provides the most successful asymmetric GARCH model for forecasting EGARCH model using a skewed student's t distribution. Wasiuzzaman ${ }^{[32]}$ reports the global financial crisis impact on the volatility of the Malaysian stock market using GARCH $(1,1)$ model and it is found to be the best fitted model according to the AIC criteria.

Since early 2003, the rapid development of Bangladesh stock market has been prominent among the emerging stock markets of South Asia. Nowadays, not only SEC but also Bangladesh Government, especially Bangladesh Bank, is very sensible to the stock market. Concerning the effectiveness of DSE which is one of the major stock markets of Bangladesh, several researchers have carried out a number of extensive research works. It has given an excellent opportunity to study their hypothesis and analysis. The most notable works, focused on market volatility and returns of DSE, are; Basher, et al. ${ }^{[33]}$, Alam, et al. ${ }^{[34]}$, Uddin and Alam ${ }^{[35]}$, Mobarek, et al. $^{[36]}$, Hassan and Chowdhury ${ }^{[37]}$, Rahman and Moazzem ${ }^{[38]}$, Hossain and Uddin ${ }^{[39]}$, Alam, et al. ${ }^{[40]}$, Hasan, et al. ${ }^{[41]}$, and Siddikee and Begum ${ }^{[42]}$. Nevertheless, a few of them uses ARCH, GARCH-M, GARCH $(p, q)$ and GARCH $(1,1)$ models with a view of finding the relationship between risks and return relationship of DSE. These researchers have identified the negative relationship between risk and return of DSE from the past statistics which indicates the fact that portfolio concept does not appear in DSE which is a vital contradictory point. In addition, Aziz and Uddin ${ }^{[4]}$ provide evidence that 2010 is the peak in terms of volatility in DSE and that volatility is declining overtime using $\operatorname{GARCH}(1,1)$ model.

Regarding the issue of volatility of stock returns, numerous researchers have recently become involved in modeling. A number of papers have examined thoroughly. Poon and Granger ${ }^{[25]}$ have evidently mentioned that GARCH performs better and dominates ARCH. Dutta ${ }^{[44]}$ found out that asymmetric GARCH models estimate better than non-asymmetric. Liu, et al. ${ }^{[45]}$ investigates the EGARCH model which achieves superior performance in predicting stock market volatility. Onwukwe, et al. ${ }^{[46]}$ stated that the GJR-GARCH model significantly outperforms which is tested by the results of error statistics and model accuracy methods.

Bangladesh stock market is an emerging one which would have a great potential for research. There is little literature on stock market volatility analysis in Bangladesh, and none of such studies has focused on GARCH type models. Motivated by these empirical studies, this paper 
examines volatility and stock return of the Bangladesh stock market by GARCH type models and testing the model forecasting ability with accuracy. In this paper, GARCH family models have been used as a tool for the DSEX index of Bangladesh stock market. The researcher has done empirical analysis on stock price volatility which is used most widely in the volatility study of GARCH family models that is defined by the mean and conditional variance equation.

\section{Data and Sample}

The time series data are used for modeling volatility on the daily closing prices of DSEX for the period from 27, November, 2001 to 30, November, 2016. The data have been collected from DSE office. The sample size consists of 3720 daily observations from closing price excluding public holidays.

\subsection{Basic Statistical Analysis}

As for the analysis purpose, the stock index is converted into stock index return to avoid complications following the algorithm expressing the difference in the logarithm between the yield of closing price of today and of yesterday's (Equation (1)), where $y_{t}$ denotes $t$ day's rate of return, $p_{t}$ denotes today's closing price, and $p_{t_{1}}$ denotes yesterday's closing price.

$$
y_{t}=\log p_{t}-\log p_{t-1} .
$$

Figure 1, shows the shape of the DSEX index during the study period. It expresses that the dependence in the volatility of the DSEX index is almost flat from 2001 to 2003 . In 2004 to 2005 , it is found a bit more volatile because of its nature of the stock market. In other words, periods of low volatility tends to be followed by periods of low volatility for a long time. Similar scenario goes for the periods of high volatility. From the year 2009 to 2010, DSEX index tends to have unexpected boom expressing market volatility. Bangladesh stock price index exhibits a downward trend after big bubble in 2010. Conclude from the graph that the Bangladesh stock market is not as volatile as the mature stock markets.

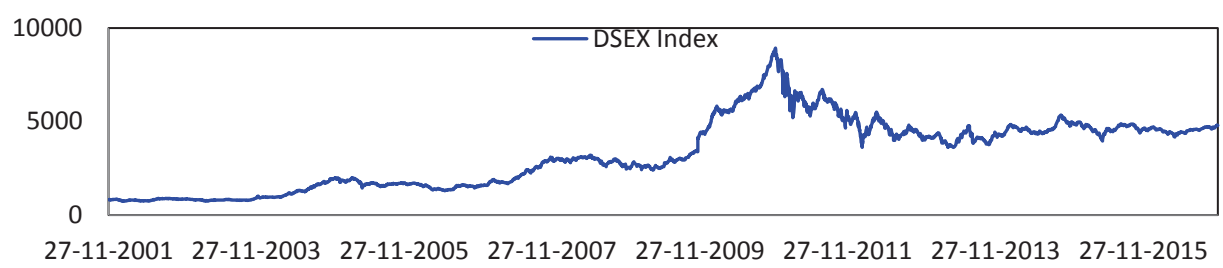

Figure 1 The daily index

Figure 2, shows the daily DSEX index returns during the sample period. It reveals that DSEX index returns are almost level from 2001 to 2003 with small returns. In 2004 to 2005, it is found a little bit increase returns because of its nature of the stock market. During the year 2009 to 2010, DSEX index returns tend to have jump to unexpected huge index returns. Khaled $^{[6]}$ finds out the biggest fall in the DSEX on 19 December 2010 which happens due to the various irregularities stock bubble burst in the Bangladesh market. After the market scam in 2011, the movement of DSEX index returns tends to have normal as expected various phases of ups and downs in market returns. 


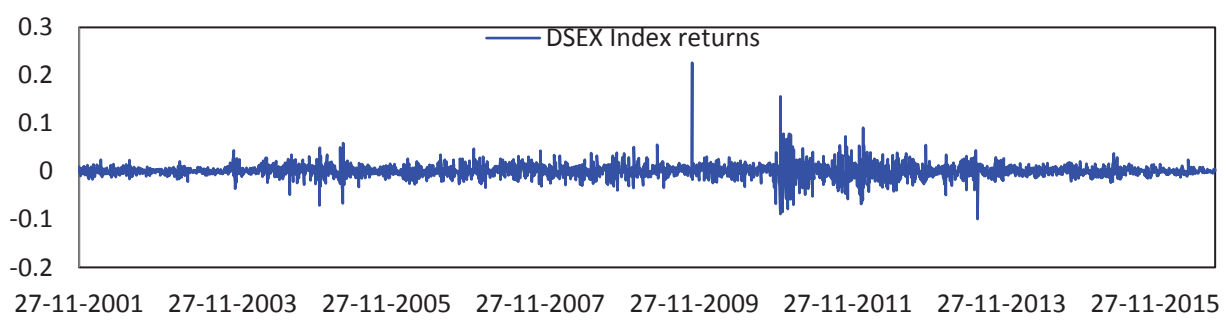

Figure 2 The daily index returns

It is needed to find out the resemblance to express a way of exposing the research data used in this paper. In this context, a brief introduction is stated about the persisting scenario in Figure 3 and Table 2.

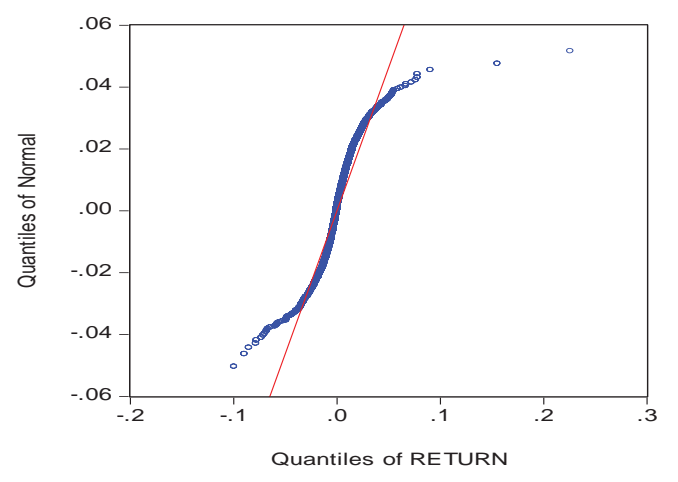

Figure 3 Q-Q plot of DSEX daily returns series

Table 2 Descriptive statistics on index returns

\begin{tabular}{ll}
\hline Series & Index Return \\
\hline Mean & 0.0006 \\
Median & 0.0004 \\
Maximum & 0.2261 \\
Minimum & -0.0992 \\
Std. Dev. & 0.0141 \\
Skewness & 1.2541 \\
Kurtosis & 30.5634 \\
Jarque-Bera & 14735.4 \\
Probability & 0.0000 \\
Observations & 3720 \\
\hline
\end{tabular}

Descriptive statistics for the return series of stock index are summarized in Table 2. The minimum and maximum stock index returns are -0.0992 and 0.2261 , respectively. It clearly defines huge difference of the mean and the standard deviation of index returns being 0.0006 and 0.0141 , respectively. In essence, the scenario depicted does not belong to a normal stock market and denotes existence of huge volatility in the stock market. Skewness is 1.2541, which 
means that right tail is particularly extreme, giving an indication that the stock market has non-symmetric returns with non-normal distributions. On the other hand, Kurtosis stock index returns is 30.5634 , which represents the skinning tail phenomenon because it has a significant value of less than 3, also expresses non-symmetric returns with non-normal distribution. Not surprisingly, the Jarque-Bera (JB) normality test is 14735.4 which strongly rejects the null hypothesis of normal distribution.

Figure 3 represents Q-Q (Quantile-Quantile) graphical examination which observes the quantiles of returns. Intend to pass research data through this graph and find out if research data has Normal Distribution or Non-normal Distribution to access if model should be able to predict the volatility of the stock index returns. Usually, the deviations from the straight line are minimal which indicates normal distribution. In this context, it is just the opposite. Bring to a close that research data has non-normal distribution.

\subsection{Testing for Heteroscedasticity}

There has been used a test for the correlogram of residuals squared $\epsilon^{2}$ using Ljung-Box (L-B) Q-statistics.

$$
y_{t}=\mu+\epsilon_{t}
$$

Q-Statistics is being considered in Table 3 for detecting autocorrelation and it is associated with probability values. From the sequence of Auto-correlation Coefficient (AC) and Partial Auto-correlation Coefficient (PAC) tests, the final results have been found in lag 20 outcomes. Considering the results, it can be stated that the validity of ARCH hypothesis exists in the Bangladesh stock market. If the probability value is less than 0.05, the null hypothesis is rejected. Alternatively, if the probability value is greater than 0.05 , the null hypothesis is accepted. In the analysis, it has found that probability value is less than $5 \%$, indicating the residuals squared data which have significantly short-term autocorrelation, i.e., residuals series and ARCH effect.

Table 3 Short-term autocorrelation and partial autocorrelation test results

\begin{tabular}{ccccc||cccccc}
\hline Lag & AC & PAC & Q-Stat & Prob & Lag & AC & PAC & Q-Stat & Prob \\
\hline 1 & 0.158 & 0.158 & 91.389 & 0.000 & 11 & 0.055 & 0.015 & 348.46 & 0.000 \\
2 & 0.114 & 0.092 & 139.37 & 0.000 & 12 & 0.048 & 0.013 & 356.87 & 0.000 \\
3 & 0.075 & 0.046 & 160.17 & 0.000 & 13 & 0.058 & 0.025 & 369.23 & 0.000 \\
4 & 0.053 & 0.026 & 170.31 & 0.000 & 14 & 0.062 & 0.025 & 383.45 & 0.000 \\
5 & 0.063 & 0.042 & 184.76 & 0.000 & 15 & 0.069 & 0.028 & 400.92 & 0.000 \\
6 & 0.077 & 0.054 & 206.45 & 0.000 & 16 & 0.081 & 0.038 & 424.89 & 0.000 \\
7 & 0.1 & 0.072 & 242.97 & 0.000 & 17 & 0.082 & 0.037 & 449.6 & 0.000 \\
8 & 0.106 & 0.069 & 284.51 & 0.000 & 18 & 0.062 & 0.017 & 463.99 & 0.000 \\
9 & 0.1 & 0.056 & 321.06 & 0.000 & 19 & 0.039 & -0.003 & 469.67 & 0.000 \\
10 & 0.067 & 0.02 & 337.43 & 0.000 & 20 & 0.034 & -0.001 & 473.97 & 0.000 \\
\hline
\end{tabular}

ARCH-LM test for the residual in the initial regression are also conducted. The null hypotheses are tested and predicted that there are no $\mathrm{ARCH}$ effects in the residual series up to 
lag 3 corresponding to return series. The results of this examination are summarized in Table 4 which provides a strong evidence for rejecting the null hypothesis. Indication of the existence of ARCH effects in the residuals series of the mean equation and therefore the variance of the returns series of DSEX index returns are non-constant.

Table 4 ARCH-LM Test for residuals of returns

\begin{tabular}{cccc}
\hline F-statistic & 8.8159 & Prob. F(3,3715) & 0.0000 \\
\hline $\mathrm{T}^{*} \mathrm{R}^{2}$-statistic & 26.2962 & Prob. Chi-Square (3) & 0.0000 \\
\hline
\end{tabular}

\subsection{Testing for Stationarity}

In time series data analysis, it is significant concern to find out if the data series is stationary (where unit root is not present) or not stationary (where unit root is exist). The term stationary focuses on modeling the dependence formation. After determining the existence of stationarity, it is necessary to be modeled in a proper way. The Augmented Dickey-Fuller test (ADF), Phillips-Perron test (PP), and the Kwiatkowski test (KPSS) are used for the testing of unit roots. In Table 5, the test statistics of ADF, PP, and KPSS test between index level and first differences are close to zero at all significance level. Bley ${ }^{[47]}$ stationarity test results also similar to this paper. From ADF unit root test indicates that null hypothesis of the existence of a unit root in the levels of index prices cannot be rejected but only exception is found in the post crisis period where the null hypothesis is rejected at the $5 \%$ level. In PP test one more exception is found in the level of index prices in post crisis period where the null hypothesis is rejected at $1 \%$ level. Finally, the KPSS test results recommend rejecting the null hypothesis of stationary for all periods. The ADF, PP, and KPSS tests show that the first differences in each period does not exist unit root, and it indicates that they can be considered as stationary series.

Table 5 ADF, PP, and KPSS tests results MacKinnon one-sided $p$-values

\begin{tabular}{llllllll}
\hline \multirow{2}{*}{ Period } & \multicolumn{4}{c}{ Levels } & & \multicolumn{3}{c}{ First differences } \\
\cline { 2 - 4 } \cline { 7 - 8 } & ADF & PP & KPSS & ADF & PP & KPSS \\
\hline Full & -1.2156 & -1.2291 & $5.9947^{* * *}$ & & $-45.6115^{* * *}$ & $-58.8626^{* * *}$ & 0.1007 \\
Pre Crisis & -0.7372 & -0.7348 & $3.4726^{* * *}$ & & $-32.2480^{* * *}$ & $-32.1980^{* * *}$ & 0.1719 \\
Crisis & -1.2700 & -1.2627 & $3.6056^{* * *}$ & & $-26.7530^{* * *}$ & $-33.5178^{* * *}$ & 0.1866 \\
Post Crisis & $-3.3889^{* *}$ & $-3.7337^{* * *}$ & $0.5928^{* *}$ & & $-33.1964^{* * *}$ & $-33.4035^{* * *}$ & 0.1084 \\
\hline
\end{tabular}

* Denote statistical significance at the $10 \%$ level;

** Denote statistical significance at the $5 \%$ level;

*** Denote statistical significance at the $1 \%$ level.

\section{Methodology}

As discussed in the earlier section, the main goal of the study is to examine the dynamic relationship between stock returns and volatility of stock indices for Bangladesh stock market. Therefore, the present study based on the GARCH $(1,1)$, GARCH-M $(1,1)$, TGARCH $(1,1)$, and EGARCH $(1,1)$ models are estimated for the DSEX index return series using the Student's 
$\mathrm{t}$ distribution. There have been used two types of methods; error statistics measurements and model accuracy to estimate the forecasting performance of different models.

\subsection{GARCH Model}

The most commonly used GARCH model is $\operatorname{GARCH}(1,1)$ that meets

$$
\sigma_{t}^{2}=\alpha_{0}+\alpha_{1} \alpha_{t-1}^{2}+\beta_{1} \sigma_{t-1}^{2}
$$

Given conditional variance equation has three components: The constant term, using the mean equation, the lag squared residuals to measure the volatility obtained and the last forecast variance (GARCH items). GARCH model assumes that there are two equations mean and variance equation. The equation follows:

$$
\alpha_{0} \geq 0, \quad \alpha_{i} \geq 0, \quad \beta_{i} \geq 0, \quad \alpha_{1}+\beta_{1}<1 .
$$

So, the next period forecast of variance is a blend of last period forecast, and last period's squared return.

\subsection{GARCH-M Model}

If fit a regression model with GARCH errors that could use the conditional standard deviation $\sigma_{t}$ as one of the regression variables when the dependent variable is return, then the market demands a higher risk premium for higher risk. Therefore, higher conditional variability would cause higher returns. The expression, where the parameter is measured in terms of standard deviation, can be observed in the risk of fluctuations in the expected degree of influence on return.

$$
y_{t}=\mu+\lambda \sigma_{t}+\epsilon_{t},
$$

where $\mu$ and $\lambda$ are constants. The parameter $\lambda$ is called the risk premium parameter. A positive $\lambda$ indicates that the return is optimistically correlated to its volatility. Other words, an increase in mean return is caused by a raise of conditional standard deviation as a substitute of increased risk.

GARCH in the mean or GARCH-M $(1,1)$ models represent the variation of a GARCH $(1$, 1) model tests whether variance can impact the mean of future returns. Where it is follow the equation:

$$
y_{t}=\mu+\lambda \sigma_{t}+\epsilon_{t}, \quad \sigma_{t}^{2}=\alpha_{0}+\alpha_{1} \alpha_{t-1}^{2}+\beta_{1} \sigma_{t-1}^{2} .
$$

If $\lambda \neq 0$, these models imply a serial correlation of returns since variance is serially correlated, and the returns depend on the variance. The studies that find that $\lambda \neq 0$ don't even agree on the sign of $\lambda$.

\subsection{TARCH Model}

TGARCH of conditional variance form in this model is set as follows:

$$
\sigma_{t}^{2}=\alpha_{0}+\sum_{i=1}^{p} \alpha_{i} \sigma_{t-i}^{2}+\sum_{j=1}^{q} \beta_{j} \sigma_{t-j}^{2}+\sum_{k=1}^{p} \gamma_{k} \sigma_{t-k}^{2} d_{t-k},
$$

where $d_{t}$ is a dummy variable, defined by the time $\epsilon_{t}<0, d_{t}=1$; then as long as $\gamma_{k} \neq 0$, the asymmetric effect exists. In the above equation, the term asymmetric effect of items, good 
information $d_{t}=0$ will have an impact time, and bad information will have another impact. The equation demonstrates the asymmetric effect and the good rumors have low impact on the volatility returns in the stock market which is associated with leverage effect.

\subsection{EGARCH Model}

The basic GARCH model assumes that positive and negative shocks of the same absolute magnitude will have the identical influence on the future conditional variances. In EGARCH model, allow for asymmetric effects between positive and negative asset returns. EGARCH models are used to model the "leverage effect" which refers to characteristic of time series on asset prices that an unexpected price drop tends to increase volatility but an unexpected price increase is not at the same magnitude. The specification of the conditional variance equation in the EGARCH model is set as,

$$
\ln \left(\sigma_{t}^{2}\right)=\alpha_{0}+\sum_{i=1}^{p} \alpha_{i}\left|\frac{\epsilon_{t-i}}{\sigma_{t-i}}\right|+\sum_{j=1}^{q} \beta_{j} \ln \left(\sigma_{t-j}^{2}\right)+\sum_{k=1}^{p} \gamma_{k} \frac{\epsilon_{t-k}}{\sigma_{t-k}} .
$$

The left side of the equation is logarithmic conditional variance, which means that the leverage effect is exponential, not quadratic. Therefore the predictive value of the conditional variance is certainly non-negative. The existence of leverage effect is tested through the hypothesis. As $\gamma_{k} \neq 0$, the effect of shocks are asymmetries. The equation shows that bad news brings more shocks than good news. Further, the variance of the right side of the equation coefficients can be positive or negative. Therefore, variance estimator equations without any restrictions make solving process that is much simpler and more flexible.

\section{Results}

\subsection{Three Period Comparison}

The results of estimating GARCH family type models specifications for the volatility and index returns are presented in this section. From the analysis in the data description part, the residuals are examined for heteroscedasticity. The ADF Test, PP Test, Q-statistics and ARCH-LM test provide strong evidence of ARCH effects in the residual series of index returns. GARCH $(1,1)$ family type models are applied to estimate the maximum likelihood method under the assumption of the Student's t distribution. In particular, it can be considered the following specifications: (i) GARCH representing Table 6, (ii) GARCH-M representing Table 7, (iii) TGARCH representing Table 8, and (iv) EGARCH representing Table 9. This section takes the analysis of the whole 15 years period. For better understanding, the whole period have been divided into three sub-periods considering the time schedules; 1) pre crisis period 2001 to 2006, 2) crisis period 2007 to 2011, and 3) post crisis period 2012 to 2016. Results are available upon request.

Firstly, the GARCH $(1,1)$ model expresses the volatility of the market situation. It has been illustrated that there are coefficients which are said to be $\alpha_{0}$ as constant, $\alpha_{1}$ as ARCH term and $\beta_{1}$ as GARCH term. These coefficients express the significant level of the volatility and returns of the stock market indices. For time series analysis, it is desirable to have stationary series. Stationary of the series can be found by summation of $\alpha_{1}+\beta_{1}$ and the value of this summation might be less than unity. In addition the sum of ARCH and GARCH coefficient $\alpha_{1}+\beta_{1}$ is close 
to one from the year 2001 to 2016 that should be indicated high or low persistence of stock return volatility. When coefficient $\alpha_{1}$ indicates low value, it shows that research data from a particular time span has less impact by rumor on the market. When coefficient $\beta_{1}$ has low value indicates the volatility of stock returns is low due to its own previous returns and alternatively high value and vice versa.

Table 6 Model=GARCH $(1,1)$, Residual distribution $=$ Student's t. Estimate equation: Return $=C(\omega), \operatorname{GARCH}=\alpha_{0}+\alpha_{1} \times \operatorname{RESID}(-1)^{2}+\beta_{1} \times \operatorname{GARCH}(-1)$

\begin{tabular}{|c|c|c|c|c|c|}
\hline \multirow{3}{*}{ Parameter } & \multirow{3}{*}{ Variable } & \multicolumn{4}{|c|}{ Periods } \\
\hline & & $(2001-2016)$ & $(2001-2006)$ & $(2007-2011)$ & $(2012-2016)$ \\
\hline & & Full & Pre Crisis & Crisis & Post Crisis \\
\hline \multirow{2}{*}{$C(\omega)$} & Coeff. & $0.0004^{c}$ & 0.0002 & $0.0018^{c}$ & 0.0002 \\
\hline & Prob. & $(0.0019)$ & $(0.2777)$ & $(0.0000)$ & $(0.3814)$ \\
\hline \multirow{2}{*}{$\alpha_{0}$} & Coeff. & $0.0000^{c}$ & $0.0000^{c}$ & $0.0000^{c}$ & $0.0000^{a}$ \\
\hline & Prob. & $(0.0001)$ & $(0.0027)$ & $(0.0001)$ & $(0.0687)$ \\
\hline \multirow{2}{*}{$\alpha_{1}$} & Coeff. & $0.2046^{c}$ & $0.2152^{c}$ & $0.2603^{c}$ & $0.1803^{c}$ \\
\hline & Prob. & $(0.0000)$ & $(0.0000)$ & $(0.0000)$ & $(0.0000)$ \\
\hline \multirow{2}{*}{$\beta_{1}$} & Coeff. & $0.7129^{c}$ & $0.6941^{c}$ & $0.7817^{c}$ & $0.7294^{c}$ \\
\hline & Prob. & $(0.0000)$ & $(0.0000)$ & $(0.0000)$ & $(0.0000)$ \\
\hline$\alpha_{1}+\beta_{1}$ & Coeff. & 0.9175 & 0.9093 & 1.0420 & 0.9097 \\
\hline \multicolumn{2}{|c|}{$\mathrm{AIC}$} & -6.3372 & -6.8144 & -5.7153 & -6.4731 \\
\hline \multicolumn{2}{|c|}{ SIC } & -6.3288 & -6.7951 & -5.6941 & -6.4508 \\
\hline \multicolumn{2}{|c|}{ ARCH LM Test } & 0.8883 & 0.2738 & 0.8602 & 0.1075 \\
\hline \multicolumn{2}{|c|}{ Log Likelihood } & 11624 & 4597 & 3419 & 3636 \\
\hline
\end{tabular}

Notes: $a, b$ and $c$ denote $10 \%, 5 \%$ and $1 \%$ level of significance. The values in the parentheses represent the $p$-value.

Table 6 reports that only crisis period (2007-2011) confidently does not satisfy the stationary condition $\alpha_{1}+\beta_{1}<1$. The coefficient of ARCH and GARCH $\left(\alpha_{1}\right.$ and $\left.\beta_{1}\right)$ are significant which reveals the persistence of information effect on the stock returns volatility. A large value of GARCH lag coefficients $\beta_{1}$ indicate that shocks to conditional variance take a long time to die out and the volatility of stock returns is high due to its own previous returns. Therefore, the volatility is 'persistent' in all periods for DSEX index returns. Low values of error coefficient $\alpha_{1}$ from all time periods suggesting that large market surprises induce relatively small revisions in future volatility. The volume of the two estimated coefficients $\left(\alpha_{1}+\beta_{1}>1\right)$ signifies high persistence of stock return volatility in the crisis period of Bangladesh stock market. On the other hand, volume of the two estimated coefficients $\left(\alpha_{1}+\beta_{1}<1\right)$ indicate that volatility shocks are decreasing found in the pre crisis and post crisis periods of Bangladesh stock market. It is considered that low volatility is followed by low volatility and high volatility is followed by high volatility. 
According to the GARCH model and the conditional variance of index returns (see boxplots Figure 4), it can be found that the volatility of crisis period is significantly bigger than the other periods.
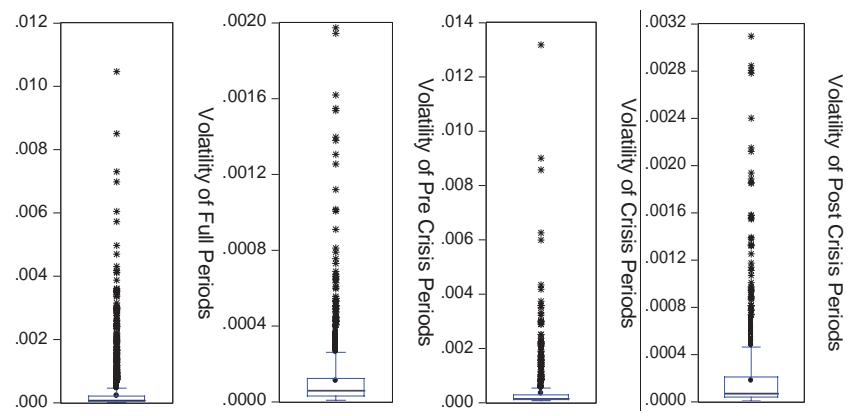

Figure 4 Volatility of different time-periods by GARCH model

Table 7 Model=GARCH $(1,1)$, Residual distribution $=$ Student's t. Estimate equation: Return $=C(\omega)+\lambda \times \mathrm{SQRT}(\mathrm{GARCH})$, $\operatorname{GARCH}=\alpha_{0}+\alpha_{1} \times \operatorname{RESID}(-1)^{2}+\beta_{1} \times \operatorname{GARCH}(-1)$

\begin{tabular}{|c|c|c|c|c|c|}
\hline \multirow{3}{*}{ Parameter } & \multirow{3}{*}{ Variable } & \multicolumn{4}{|c|}{ Periods } \\
\hline & & $(2001-2016)$ & $(2001-2006)$ & $(2007-2011)$ & $(2012-2016)$ \\
\hline & & Full & Pre Crisis & Crisis & Post Crisis \\
\hline \multirow{2}{*}{$C(\omega)$} & Coeff. & -0.0004 & $-0.0008^{a}$ & $0.0023^{b}$ & -0.0001 \\
\hline & Prob. & $(0.1132)$ & $(0.0597)$ & $(0.0400)$ & $(0.7705)$ \\
\hline \multirow{2}{*}{$\lambda$} & Coeff. & $0.1102^{c}$ & $0.1565^{c}$ & -0.0342 & $0.0472^{b}$ \\
\hline & Prob. & $(0.0012)$ & $(0.0135)$ & $(0.6883)$ & $(0.4457)$ \\
\hline \multirow{2}{*}{$\alpha_{0}$} & Coeff. & $0.0000^{c}$ & $0.0000^{c}$ & $0.0000^{c}$ & $0.0000^{a}$ \\
\hline & Prob. & $(0.0001)$ & $(0.0023)$ & 0.0001 & $(0.0653)$ \\
\hline \multirow{2}{*}{$\alpha_{1}$} & Coeff. & $0.2096^{c}$ & $0.2186^{c}$ & $0.2540^{c}$ & $0.1810^{c}$ \\
\hline & Prob. & $(0.0000)$ & $(0.0000)$ & $(0.0000)$ & $(0.0000)$ \\
\hline \multirow{2}{*}{$\beta_{1}$} & Coeff. & $0.7096^{c}$ & $0.6920^{c}$ & $0.7897^{c}$ & $0.7286^{c}$ \\
\hline & Prob. & $(0.0000)$ & $(0.0000)$ & $(0.0000)$ & $(0.0000)$ \\
\hline$\alpha_{1}+\beta_{1}$ & Coeff. & 0.9192 & 0.9106 & 1.0437 & 0.9096 \\
\hline \multicolumn{2}{|c|}{$\mathrm{AIC}$} & -6.3401 & -6.8185 & -5.7138 & -6.4719 \\
\hline \multicolumn{2}{|c|}{$\mathrm{SIC}$} & -6.3300 & -6.7954 & -5.6883 & -6.4451 \\
\hline \multicolumn{2}{|c|}{ ARCH LM Test } & 0.8882 & 0.3337 & 0.8615 & 0.1072 \\
\hline \multicolumn{2}{|c|}{ Log Likelihood } & 11630 & 4601 & 3419 & 3636 \\
\hline
\end{tabular}

Notes: $a, b$ and $c$ denote $10 \%, 5 \%$ and $1 \%$ level of significance. The values in the parentheses represent the $p$-value.

Secondly, the GARCH-M $(1,1)$ model is predictable by allowing the mean equation of the 
return series which depends on a function of the conditional variance of the standard deviation $\sigma_{t}$. The return rate formula includes the terms of the standard deviation $\sigma_{t}$ which is in sequence that integrates the risk measurement inside the whole process of revenue generation. During this prediction, the coefficient $\lambda$ of conditional standard deviation should certainly be positive. The outcome is precisely the situation, the conditional standard deviation and that has much larger expected value related to high rates of return.

Table 7 reports that full period, pre crisis period, and post crisis period risk premium of $\sigma_{t}^{2}$ in the mean equation is positive for the index, which indicates that the mean of the return series depends on earlier period innovations and historical conditional variance. However, volatility increases lead to the decrease of returns in crisis period. The risk premiums of crisis period are -0.0342 states that lower returns are expected for assets with high level of risk.

The conditional variances of index returns have been calculated by the GARCH-M model in different periods which have been plotted in Figure 5. The volatility of crisis period is significantly bigger than the other periods.
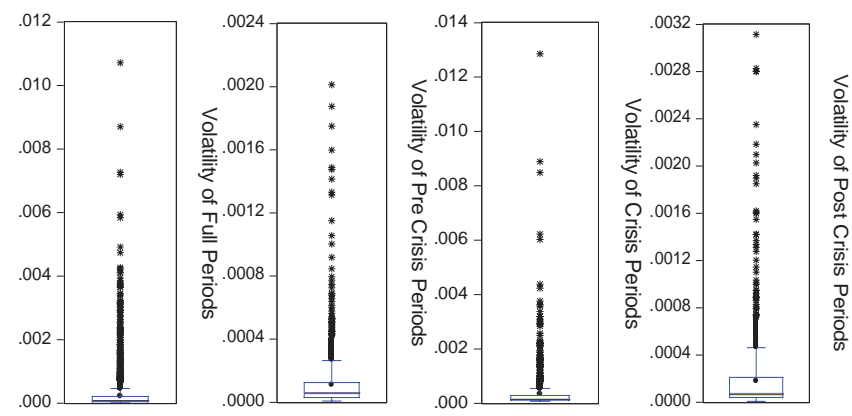

Figure 5 Volatility of different time-periods by GARCH-M model

The stock market crash on December 19, 2010 is an extreme example when large moves in prices lead to bigger moves. Khaled ${ }^{[6]}$ mentioned in his report that during the time, Bangladesh Bank makes the decision to increase Cash Reserve Ratio (CRR) and Statutory Liquidity Ratio (SLR) that have been restricted more than $10 \%$ investment of deposited money. It creates liquidity crisis and the results show that the market is going down due to force selling. At the same time, BSEC takes another decision of splitting share face value and makes uniform face value at BDT 10. Though splitting share face value is considered as a vital reason for unpredictable climbing of index, splitting shares actually do not modify revenue or assets of a company and cannot affect the shares price. Therefore imperfect decision leads to an abnormally increased liquidity of the market and changes market capitalization.

Thirdly, TGARCH $(1,1)$ model has been estimated with asymmetric conditional volatility process for DSEX index returns. Model parameters are obliged to satisfy the positive condition. According to this model, it can be observed that coefficient $\gamma_{1}$ is significantly different from zero implying that the series has asymmetric (leverage) effect. Asymmetric is caused by the fact that negative returns have a greater influence on future volatility than the positive returns in index. The aggregate financial leverage is correlated with stock returns volatility according to the predication of financial leverage theory. Here it can be found out that stock returns 
volatility is higher during stock market crisis periods than during expansions of the operating leverage theory predictions. Further evidence depicts that stock returns volatility increases offer a huge fall in stock prices.

Table 8 results indicate $\gamma_{1}$ values are positive and also statistically significant for all periods' values except pre crisis period which has positive values but carries insignificant parameter. The outcome suggests that Bangladesh stock market has leverage effect in crisis and post crisis periods except the pre crisis period. In Bangladesh stock market, the effect of "bad rumors" is higher than the "good rumors" which increases the volatility. The significance of this coefficient indicates that bad rumors have a larger effect than the same magnitude of good rumors on the increases volatility.

Table 8 Model=GARCH $(1,1)$, Residual distribution $=$ Student's t. Estimate equation: Return $=C(\omega), \mathrm{GARCH}=\alpha_{0}+\alpha_{1} \times \mathrm{RESID}$ $(-1)^{2}+\beta_{1} \times \operatorname{GARCH}(-1)+\gamma_{1} \times \operatorname{RESID}(-1)<0$

\begin{tabular}{|c|c|c|c|c|c|}
\hline \multirow{3}{*}{ Parameter } & \multirow{3}{*}{ Variable } & \multicolumn{4}{|c|}{ Periods } \\
\hline & & $(2001-2016)$ & $(2001-2006)$ & $(2007-2011)$ & $(2012-2016)$ \\
\hline & & Full & Pre Crisis & Crisis & Post Crisis \\
\hline \multirow{2}{*}{$C(\omega)$} & Coeff. & $0.0003^{b}$ & 0.0001 & $0.0016^{c}$ & 0.0000 \\
\hline & Prob. & $(0.0225)$ & $(0.4036)$ & $(0.0000)$ & $(0.8308)$ \\
\hline \multirow{2}{*}{$\alpha_{0}$} & Coeff. & $0.0000^{c}$ & $0.0000^{c}$ & $0.0000^{c}$ & $0.0000^{a}$ \\
\hline & Prob. & $(0.0001)$ & $(0.0032)$ & $(0.0000)$ & $(0.0890)$ \\
\hline \multirow{2}{*}{$\alpha_{1}$} & Coeff. & $0.1650^{c}$ & $0.2007^{c}$ & $0.0444^{a}$ & $0.1173^{c}$ \\
\hline & Prob. & $(0.0000)$ & $(0.0000)$ & $(0.0891)$ & $(0.0000)$ \\
\hline \multirow{2}{*}{$\beta_{1}$} & Coeff. & $0.8123^{c}$ & $0.7926^{c}$ & $0.8491^{c}$ & $0.8404^{c}$ \\
\hline & Prob. & $(0.0000)$ & $(0.0000)$ & $(0.0000)$ & $(0.0000)$ \\
\hline \multirow{2}{*}{$\gamma_{1}$} & Coeff. & $0.0867^{c}$ & 0.0363 & $0.2599^{c}$ & $0.1075^{c}$ \\
\hline & Prob. & $(0.0003)$ & $(0.3517)$ & $(0.0000)$ & $(0.0011)$ \\
\hline$\alpha_{1}+\beta_{1}$ & Coeff. & 0.9773 & 0.9933 & 0.8935 & 0.9577 \\
\hline \multicolumn{2}{|c|}{$\mathrm{AIC}$} & -6.3410 & -6.8137 & -5.7332 & -6.4820 \\
\hline \multicolumn{2}{|c|}{$\mathrm{SIC}$} & -6.3308 & -6.7905 & -5.7077 & -6.4551 \\
\hline \multicolumn{2}{|c|}{ ARCH LM Test } & 0.8768 & 0.3272 & 0.8497 & 0.1243 \\
\hline \multicolumn{2}{|c|}{ Log Likelihood } & 11632 & 4598 & 3431 & 3642 \\
\hline
\end{tabular}

Notes: $a, b$ and $c$ denote $10 \%, 5 \%$ and $1 \%$ level of significance. The values in the parentheses represent the $p$-value.

The boxplots in Figure 6 show the conditional variance of index return calculated by the TGARCH model in the variety periods. Similarly as previous results, it can be found that the volatility of crisis period is significantly bigger than the other periods.

Finally, in EGARCH $(1,1)$ model, there is no need for nonnegative restriction of the parameters. Leverage effect is a negative correlation between the past return and future volatility of 
return and it is a ratio of debt/equity. The higher leverage occurs due to negative return which translates to low equity prices meaning that a higher debt to equity ratio of a firm. Whereas a positive shock has less effect on the conditional variance compared to a negative news or shock; it is known as leverage effect.
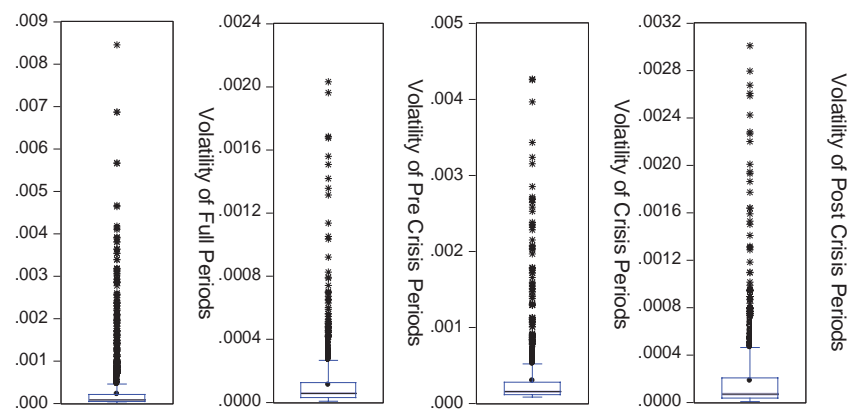

Figure 6 Volatility of different time-periods by TGARCH model

Table 9 Model=GARCH $(1,1)$, Residual distribution = Student's t. Estimate equation:

Return $=C(\omega), \quad \operatorname{GARCH}=\alpha_{0}+\alpha_{1} \times \quad(\operatorname{RESID} \quad(-1) / \operatorname{SQRT}(\operatorname{GARCH}(-1)))+\beta_{1} \times$ $\mathrm{LOG}(\mathrm{GARCH}(-1))+\gamma_{1} \times \mathrm{RESID} / \mathrm{SQRT}(\mathrm{GARCH}(-1)<0)$

\begin{tabular}{|c|c|c|c|c|c|}
\hline \multirow{3}{*}{ Parameter } & \multirow{3}{*}{ Variable } & \multicolumn{4}{|c|}{ Periods } \\
\hline & & $(2001-2016)$ & $(2001-2006)$ & $(2007-2011)$ & $(2012-2016)$ \\
\hline & & Full & Pre Crisis & Crisis & Post Crisis \\
\hline \multirow{2}{*}{$C(\omega)$} & Coeff. & 0.0002 & 0.0001 & $0.0016^{c}$ & -0.0001 \\
\hline & Prob. & $(0.1023)$ & $(0.5682)$ & $(0.0000)$ & $(0.7920)$ \\
\hline \multirow{2}{*}{$\alpha_{0}$} & Coeff. & $-0.4919^{c}$ & $-0.6946^{c}$ & $-0.8137^{c}$ & $-0.3437^{c}$ \\
\hline & Prob. & $(0.0000)$ & $(0.0000)$ & $(0.0000)$ & $(0.0000)$ \\
\hline \multirow{2}{*}{$\alpha_{1}$} & Coeff. & $0.3012^{c}$ & $0.2953^{c}$ & $0.2721^{c}$ & $0.2819^{c}$ \\
\hline & Prob. & $(0.0000)$ & $(0.0000)$ & $(0.0000)$ & $(0.0000)$ \\
\hline \multirow{2}{*}{$\beta_{1}$} & Coeff. & $0.7710^{c}$ & $0.6593^{c}$ & $0.7282^{c}$ & $0.6867^{c}$ \\
\hline & Prob. & $(0.0000)$ & $(0.0000)$ & $(0.0000)$ & $(0.0000)$ \\
\hline \multirow{2}{*}{$\gamma_{1}$} & Coeff. & $-0.0594^{c}$ & -0.0207 & $-0.1188^{c}$ & $-0.0597^{c}$ \\
\hline & Prob. & $(0.0000)$ & $(0.2994)$ & $(0.0000)$ & $(0.0005)$ \\
\hline$\alpha_{1}+\beta_{1}$ & Coeff. & 1.0722 & 0.9546 & 1.0003 & 0.9686 \\
\hline \multicolumn{2}{|c|}{$\mathrm{AIC}$} & -6.3386 & -6.8148 & -5.7282 & -6.4889 \\
\hline \multicolumn{2}{|c|}{$\mathrm{SIC}$} & -6.3285 & -6.7916 & -5.7027 & -6.4621 \\
\hline \multicolumn{2}{|c|}{ ARCH LM Test } & 0.9054 & 0.1018 & 0.8833 & 0.3103 \\
\hline \multicolumn{2}{|c|}{ Log Likelihood } & 11627 & 4599 & 3428 & 3646 \\
\hline
\end{tabular}

Notes: $a, b$ and $c$ denote $10 \%, 5 \%$ and $1 \%$ level of significance. The values in the parentheses represent the $p$-value.

In Table 9, it indicates that all the estimated coefficients are statistically significant. The 
parameter $\gamma_{1}$ is statistically significant for all period with a positive sign, which is a sign of the continuation of leverage effect and that bad rumors increase the volatility term. Leverage effect is found when $\gamma_{1}$ is significant and negative in each periods. The results show strong evidence that the positive shocks imply a higher next period conditional variance than negative shocks of the same sign, which indicates the existence of leverage effects in the returns of the DSEX index in each periods.

The boxplots are presented in the article showing conditional variance of index return calculated by the EGARCH model in different periods. Followed by the previous results, the volatility of crisis period is significantly bigger than the other periods.
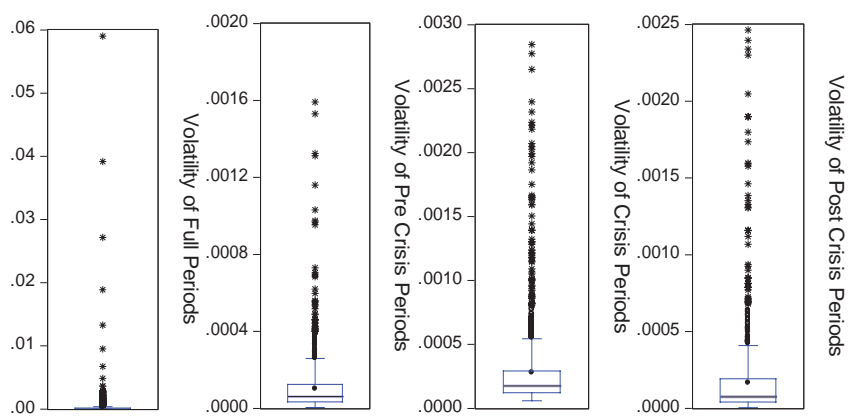

Figure 7 Volatility of different time-periods by EGARCH model

\subsection{Forecasting Performance Comparison}

It is found that from various significant aspects of forecasting exercise there is another vital aspect which is comparing forecasting performance of competing. In forecasting performance of DSEX index returns are compared by all error terms (so called "error statistic measurements") through Root Mean Squared Error (RMSE), Mean Absolute Error (MAE), Mean Abs. Percent Error (MAPE), and Theil Inequality Coefficient (TIC) which are discussed in the first section. The second section follows the forecasting performance which are estimated different GARCH models by model accuracy and these are determined on the basis of the Akaike Information Criteria (AIC), Schwarz Information Criteria (SIC), Log-likelihood (LL), and ARCH-LM test.

Table 10 focuses on forecast performance of estimated different models by error statistics. The overall results of forecasting performance suggested that GARCH and TGARCH model slightly better forecasting as compared to EGARCH and GARCH-M as it has minimum errors. The results show that the GARCH model outperformed all the other models. In sub periods analysis comparing the performance of different model is found the values which have very small difference. In recent paper, Lim and Sek ${ }^{[48]}$ compared the performances of GARCH-type models in Malaysia stock market and their results are almost parallel to these results. This finding is also steady with the evidence of Srinivasan and Ibrahim ${ }^{[49]}$ that relatively GARCH model is found superior in emerging markets. Based on results of GARCH model, it is the best in pre-crisis periods. In post crisis periods EGARCH model is performing the best. Surprisingly, crisis period follows GARCH-M model which is the best to capture the stock market volatility in Bangladesh. 
Table 10 Forecasting performance of estimated different models by error statistics

\begin{tabular}{|c|c|c|c|c|c|c|}
\hline Periods & Model & RMSE & MAE & MAPE & $\mathrm{TIC}$ & Rank \\
\hline \multirow{4}{*}{ Full } & $\operatorname{GARCH}(1,1)$ & $0.0140^{1}$ & $0.0089^{1}$ & $120.6334^{3}$ & $0.9727^{1}$ & 1 \\
\hline & GARCH-M(1,1) & $0.0146^{4}$ & $0.0097^{3}$ & $124.1275^{4}$ & $0.9896^{4}$ & 4 \\
\hline & TGARCH(1,1) & $0.0141^{2}$ & $0.0090^{1}$ & $114.4704^{2}$ & $0.9793^{2}$ & 2 \\
\hline & EGARCH$(1,1)$ & $0.0141^{2}$ & $0.0091^{2}$ & $109.6304^{1}$ & $0.9847^{3}$ & 3 \\
\hline \multirow{4}{*}{ Pre-Crisis } & $\operatorname{GARCH}(1,1)$ & $0.0100^{1}$ & $0.0070^{1}$ & $110.8221^{3}$ & $0.9808^{1}$ & 1 \\
\hline & GARCH-M $(1,1)$ & $0.0113^{4}$ & $0.3461^{4}$ & $116.3476^{4}$ & $0.9847^{2}$ & 4 \\
\hline & TGARCH $(1,1)$ & $0.0101^{2}$ & $0.0070^{1}$ & $107.8778^{2}$ & $0.9849^{3}$ & 2 \\
\hline & $\operatorname{EGARCH}(1,1)$ & $0.0102^{3}$ & $0.0070^{1}$ & $104.3304^{1}$ & $0.9847^{4}$ & 3 \\
\hline \multirow{4}{*}{ Crisis } & $\operatorname{GARCH}(1,1)$ & $0.0184^{2}$ & $0.0119^{3}$ & $217.5728^{4}$ & $0.9081^{1}$ & 4 \\
\hline & GARCH-M(1,1) & $0.0184^{1}$ & $0.0117^{1}$ & $202.4037^{3}$ & $0.9171^{2}$ & 1 \\
\hline & TGARCH $(1,1)$ & $0.0185^{2}$ & $0.0118^{2}$ & $200.2736^{2}$ & $0.9186^{3}$ & 3 \\
\hline & EGARCH$(1,1)$ & $0.0184^{1}$ & $0.0118^{2}$ & $200.1840^{1}$ & $0.9187^{4}$ & 2 \\
\hline \multirow{4}{*}{ Post Crisis } & $\operatorname{GARCH}(1,1)$ & $0.0130^{2}$ & $0.0086^{2}$ & $105.3941^{3}$ & $0.9861^{2}$ & 3 \\
\hline & GARCH-M $(1,1)$ & $0.0147^{3}$ & $0.0095^{3}$ & $107.4839^{4}$ & $0.8276^{1}$ & 4 \\
\hline & TGARCH $(1,1)$ & $0.0130^{2}$ & $0.0085^{1}$ & $100.1272^{1}$ & $0.9965^{4}$ & 2 \\
\hline & $\operatorname{EGARCH}(1,1)$ & $0.0129^{1}$ & $0.0085^{1}$ & $100.2742^{2}$ & $0.9958^{3}$ & 1 \\
\hline
\end{tabular}

Notes: In error statistic measurements through root mean squared error (RMSE), mean absolute error (MAE), mean abs. percent error (MAPE), and Theil inequality coefficient (TIC) are discussed.

Table 11 focuses on forecast performance of estimated different models by model accuracy. There are four different testing criteria out of which we have already demonstrated ARCH LM Test (GARCH type models do not exhibit any additional ARCH effect remaining in the residuals of the models), so it is only considered the lowest value of AIC SIC and conversely highest value of Log Likelihood from the Student's t distribution. This result shows that TGARCH model is the best followed by the EGARCH model, GARCH model tends to be last. This finding is consistent with the evidence of Srinivasan and Ibrahim ${ }^{[49]}$ that relatively asymmetric GARCH model is found superior in forecasting the emerging India market. These criteria reveal that TGARCH model and EGARCH model have better estimates and the series compared to the GARCH model and GARCH-M model.

\section{Conclusion}

In this paper the volatility of the Bangladesh stock market and index returns are evaluated utilizing GARCH family type models. From the results of the test-statistics, it is found that the rates of return series have a heteroscedastic phenomenon. In this study, several important results are obtained. First, the DSE returns have been modeled by using GARCH types of models and it is used to study the volatility of DSEX index. Applying the both symmetric and asymmetric models, it is to capture the most common stylized facts about index returns such as volatility and leverage effects. These models are GARCH $(1,1)$, GARCH-M $(1,1)$, 
TGARCH $(1,1)$, and EGARCH $(1,1)$ models for assuming student's t-distribution method. In all these four models the volatility in the stock index and significant ARCH effect is proved. Second, the results from the GARCH-M models show that the risk premium in crisis period is negative which indicates high-risk and low-yield. Third, evaluation of asymmetric TGARCH and EGARCH models results indicate that the most important leverage effect is existence in the Bangladesh stock index. DSE exists with a significant leverage effect and the role of "bad rumors" is clearly stronger than "good rumors" which shows that our investors are often more sensitive to decline the stocks as a result of avoiding risk. The models provide useful information concerning the fluctuation of volatility indicating that the use of GARCH family type models is the most appropriate models to generate the volatility of index.

Table 11 Forecasting performance of estimated different models by model accuracy

\begin{tabular}{|c|c|c|c|c|c|}
\hline Periods & Model & $\mathrm{AIC}$ & $\mathrm{SIC}$ & LL & Rank \\
\hline \multirow{4}{*}{ Full } & $\operatorname{GARCH}(1,1)$ & $-6.3372^{4}$ & $-6.3288^{3}$ & $11624^{4}$ & 4 \\
\hline & GARCH-M $(1,1)$ & $-6.3401^{2}$ & $-6.300^{2}$ & $11630^{2}$ & 2 \\
\hline & TGARCH $(1,1)$ & $-6.3410^{1}$ & $-6.3308^{1}$ & $11632^{1}$ & 1 \\
\hline & $\operatorname{EGARCH}(1,1)$ & $-6.3386^{3}$ & $-6.3285^{4}$ & $11627^{3}$ & 3 \\
\hline \multirow{4}{*}{ Pre-Crisis } & $\operatorname{GARCH}(1,1)$ & $-6.8144^{3}$ & $-6.7951^{2}$ & $4597^{4}$ & 3 \\
\hline & GARCH-M(1,1) & $-6.8185^{1}$ & $-6.7954^{1}$ & $4601^{1}$ & 1 \\
\hline & TGARCH $(1,1)$ & $-6.8137^{4}$ & $-6.7905^{4}$ & $4598^{3}$ & 4 \\
\hline & $\operatorname{EGARCH}(1,1)$ & $-6.8148^{2}$ & $-6.7916^{3}$ & $4599^{2}$ & 2 \\
\hline \multirow{4}{*}{ Crisis } & $\operatorname{GARCH}(1,1)$ & $-5.7153^{3}$ & $-5.6941^{3}$ & $3419^{4}$ & 3 \\
\hline & GARCH-M(1,1) & $-5.7138^{4}$ & $-5.6883^{4}$ & $3419^{3}$ & 4 \\
\hline & TGARCH $(1,1)$ & $-5.7332^{1}$ & $-5.7077^{1}$ & $3431^{1}$ & 1 \\
\hline & $\operatorname{EGARCH}(1,1)$ & $-5.7282^{2}$ & $-5.7027^{2}$ & $3428^{2}$ & 2 \\
\hline \multirow{4}{*}{ Post Crisis } & $\operatorname{GARCH}(1,1)$ & $-6.4731^{3}$ & $-6.4508^{3}$ & $3636^{4}$ & 3 \\
\hline & GARCH-M $(1,1)$ & $-6.4719^{4}$ & $-6.4451^{4}$ & $3636^{3}$ & 4 \\
\hline & TGARCH $(1,1)$ & $-6.4820^{2}$ & $-6.4551^{2}$ & $3642^{2}$ & 2 \\
\hline & $\operatorname{EGARCH}(1,1)$ & $-6.4889^{1}$ & $-6.4621^{1}$ & $3646^{1}$ & 1 \\
\hline
\end{tabular}

Notes: Use minimum Akaike Information Criteria (AIC), minimum Schwarz Information Criteria (SIC), and the maximum Log-likelihood (LL) were discussed.

This study investigates that there is no particular model evidently fitted for all series evaluation in daily index of emerging Bangladesh. The GARCH type models have been evaluated based on their forecasting ability of the future returns which is considered by error statistic measurements. According to the outcome it can be concluded that there have been very small differences in the performance of these four models. However, the rank shows that GARCH model dominates the EGARCH GARCH-M, and TGARCH models. GARCH model is the most proper model for modeling the volatility and returns of DSEX index. The GARCH family type models are also evaluated the methods of measuring model accuracy to the forecasting 
performance under AIC, SIC, and Log Likelihood accuracy criteria. The evidence of models suggests that an integrated TGARCH model dominates the EGARCH, GARCH-M, and GARCH models. TGARCH $(1,1)$ model is more accurate to describe the DSEX index.

To summary, the key contribution of this article is that the study is about an emerging Bangladesh stock market which is rarely studied before. It is needed to consider more carefully where different models capture the different characteristics of the stock market. Some interesting conclusions are found, for example, there are noteworthy "low-yield associated with high-risk" observable fact and a significant increased volatility during the crisis period for DSE market. The leverage effect exists in each period. This outcome further implies that the GARCH and TGARCH models might be more appropriate than the additional two models when applying risk management strategies for Bangladesh stock index returns. Some more variables can be added into the models to improve the accuracy and the contagion between several stock markets can also be measured in the further study. Overall, the results show that the nature of information slightly different in separate periods.

The Bangladesh stock market is considered to be one of the important emerging markets in South Asia, and much attention has been given to this market by foreign investors and researchers. It can be concluded with some proposal that preparing an essential national fund is an alternative before facing crisis. In common control mechanism some rules are associated such as price limits and volume quotas which are restructured relative to the status of both the economy and Bangladesh stock market trading cycles. Altogether, a developing marketoriented economy will necessitate profound, more effective and well-regulated financial markets which has great combination with global trade and finance. The findings of the article would help the government to formulate policies to improve market maturity. Therefore, practically, the findings of this study might be interesting for investors, traders, and regulators who plan to launch the trading of stock index in future domestically or internationally.

\section{Acknowledgment}

An earlier version of this paper was presented at the 2016 Service Systems Engineering Conference \& 2016 IEEE Symposium on Analytics and Risk Conference. Thanks go to some participants who made comments and suggestions for us to improve the paper. Financial support provided by the Chinese Academy of Sciences and The World Academy of Sciences are gratefully acknowledged. And special thanks go to Dhaka Stock Exchange authority for its support.

\section{References}

[1] Elliott L. New-wave economies going for growth, global economy. The Guardian on 18 December, 2012. www.theguardian.com/world/2012/dec/18/booming-economies-beyond-brics.

[2] Oseni I O, Nwosa P I. Stock market volatility and macroeconomic variables volatility in Nigeria: An exponential GARCH Approach. European Journal of Business and Management, 2011, 3(12): 43-53.

[3] Hasan M S, Rahman R A, Hossain S Z. Corporate accruals practices of listed companies in Bangladesh. European Journal of Economics and Management, 2014, 1(1): 17-46.

[4] Islam K A, Zaman M. Causes \& consequences of stock market crash in Bangladesh: An empirical investigation. Bangladesh Research Foundation Journal, 2014, 3(1): 191-210. 
[5] Ahmed S A C G T. A struggle to fix flaws in index. The Daily Star on 20 October, 2011. http://archive. thedailystar.net/newDesign/news-details.php?nid=206668.

[6] Khaled K I. Investigation report of probe committee. Bangladesh: Academic Press, 2011, 85-107.

[7] Arestis P, Demetriades P O, Luintel K B. Financial development and economic growth: The role of stock markets. Journal of Money, Credit and Banking, 2001, 33(1): 16-41.

[8] Schwert G W. Why does stock market volatility change over time? The Journal of Finance, 1989, 44(5): $1115-1153$.

[9] Black F. Stuedies of stock price volatility changes. Proceedings of the 1976 Meetings of the Business and Economics Statistics Section, American Statistical Association, 1976, 177-181.

[10] Gencay R, Selcuk F. Extreme value theory and value-at-risk: Relative performance in emerging markets. International Journal of Forecasting, 2004, 20(2): 287-303.

[11] Llaudes R, Salman F, Chivakul M. The impact of the great recession on emerging markets. IMF Working Papers, 2010, 1-34.

[12] Baker M, Wurgler J. Investor sentiment in the stock market. The Journal of Economic Perspectives, 2007, 21(2): 129-151.

[13] Beer F, Hervé F, Zouaoui M. Is big brother watching us? Google, investor sentiment and the stock market. Economics Bulletin, Forthcoming, 2012.

[14] Li W, Wang S S, Rhee G. Differences in herding: Individual vs. institutional investors. In Asian Finance Association (AsianFA), 2015, Conference Paper.

[15] Engle R F. Autoregressive conditional heteroscedasticity with estimates of the variance of United Kingdom inflation. Econometrica, 1982, 50(4): 987-1007.

[16] Bollerslev T. Generalized autoregressive conditional heteroskedasticity. Journal of Econometrics, 1986, 31(3): 307-327.

[17] Nelson D B. Conditional heteroskedasticity in asset returns: A new approach. Econometrica: Journal of the Econometric Society, 1991, 59(2): 347-370.

[18] Glosten L R, Jagannathan R, Runkle D E. On the relation between the expected value and the volatility of the nominal excess return on stocks. The Journal of Finance, 1993, 48(5): 1779-1801.

[19] Zakoian J M. Threshold heteroskedastic models. Journal of Economic Dynamics and Control, 1994, 18(5): 931-955.

[20] Nor M, Shaari A H, Shamiri A. Modeling and forecasting volatility of the Malaysian and the Singaporean stock indices using asymmetric GARCH models and non-normal densities. Malaysian Journal of Mathematical Sciences, 2007, 1(1): 83-102.

[21] Ezzat H. The application of GARCH and EGARCH in modeling the volatility of daily stock returns during massive shocks: The empirical case of Egypt. International Research Journal of Finance and Economics, 2012, 96: 143-154.

[22] Ehlert A, Fiebig U R, Janssen A, et al. Joint extremal behavior of hidden and observable time series with applications to GARCH processes. Extremes, 2015, 18(1): 109-140.

[23] Brailsford T J, Faff R W. An evaluation of volatility forecasting techniques. Journal of Banking \& Finance, 1996, 20(3): 419-438.

[24] Abdalla S Z S, Winker P. Modelling stock market volatility using univariate GARCH models: Evidence from Sudan and Egypt. International Journal of Economics and Finance, 2012, 4(8): 161-176.

[25] Poon S H, Granger C W. Forecasting volatility in financial markets: A review. Journal of Economic Literature, 2003, 41(2): 478-539.

[26] Allen D E, Singh A K, Powell R J. EVT and tail-risk modelling: Evidence from market indices and volatility series. The North American Journal of Economics and Finance, 2013, 26: 355-369.

[27] Hai-nan H, Wei Z. Evaluation on volatility forecasting performance of GARCH type models. Chinese Journal of Management Science, 2007, 15(6): 13-19.

[28] Awartani B M, Corradi V. Predicting the volatility of the S\&P-500 stock index via GARCH models: The role of asymmetries. International Journal of Forecasting, 2005, 21(1): 167-183.

[29] Ederington L H, Guan W. Forecasting volatility. Journal of Futures Markets, 2005, 25(5): 465-490.

[30] Liu H C, Chiang S M, Cheng N Y P. Forecasting the volatility of S\&P depositary receipts using GARCHtype models under intraday range-based and return-based proxy measures. International Review of Economics \& Finance, 2012, 22(1): 78-91. 
[31] Alberg D, Shalit H, Yosef R. Estimating stock market volatility using asymmetric GARCH models. Applied Financial Economics, 2008, 18(15): 1201-1208.

[32] Wasiuzzaman S. Impact of the global financial crisis on the volatility of the Malaysian stock market. International Conference on E-business, Management and Economics — ICEME 2010(IEEE), 2010, 3: 79-84.

[33] Basher S A, Hassan M K, Islam A M. Time-varying volatility and equity returns in Bangladesh stock market. Applied Financial Economics, 2007, 17(17): 1393-1407.

[34] Alam M M, Alam K A, Uddin M G S. Market depth and risk return analysis of Dhaka stock exchange: An empirical test of market efficiency. ASA University Review, 2007, 1(1): 93-101.

[35] Uddin M G S, Alam M M. The impacts of interest rate on stock market: Empirical evidence from Dhaka stock exchange. South Asian Journal of Management and Sciences, 2007, 1(2): 123-132.

[36] Mobarek A, Mollah A S, Bhuyan R. Market efficiency in emerging stock market evidence from Bangladesh. Journal of Emerging Market Finance, 2008, 7(1): 17-41.

[37] Hassan M K, Chowdhury S. Efficiency of Bangladesh stock market: Evidence from monthly index and individual firm data. Applied Financial Economics, 2008, 18(9): 749-758.

[38] Rahman M T, Moazzem K G. Capital market of Bangladesh: Volatility in the Dhaka stock exchange and role of regulators. International Journal of Business and Management, 2011, 6(7): 86-93.

[39] Hossain M S, Uddin M G S. Efficiency analysis and volatility effect of Bangladesh stock market. Cambridge Business \& Economics Conference, 2011, 1-31.

[40] Alam M M, Yasmin S, Rahman M, et al. Effect of policy reforms on market efficiency: Evidence from Dhaka stock exchange. Economics Research International, 2011, 1-8.

[41] Hasan M Z, Kamil A A, Mustafa A, et al. Relationship between risk and expected returns: Evidence from the Dhaka stock exchange. Procedia Economics and Finance, 2012, 2: 1-8.

[42] Siddikee M N, Begum N N. Volatility of Dhaka stock exchange. International Journal of Economics and Finance, 2016, 8(5): 220-229.

[43] Aziz M S I, Uddin M N. Volatility estimation in the Dhaka stock exchange returns by GARCH models. Asian Business Review, 2015, 4(1): 41-49.

[44] Dutta A. A study of the NSE's volatility for very small period using asymmetric GARCH models. Vilakshan: The XIMB Journal of Management, 2010, 7(2): 107-120.

[45] Liu H C, Hung J C. Forecasting S\&P-100 stock index volatility: The role of volatility asymmetry and distributional assumption in GARCH models. Expert Systems with Applications, 2010, 37(7): 4928-4934.

[46] Onwukwe C E, Bassey B E E, Isaac I O. On modeling the volatility of Nigerian stock returns using GARCH models. Journal of Mathematics Research, 2011, 3(4): 31-43.

[47] Bley J. Are GCC stock markets predictable?. Emerging Markets Review, 2011, 12(3): 217-237.

[48] Lim C M, Sek S K. Comparing the performances of GARCH-type models in capturing the stock market volatility in Malaysia. Procedia Economics and Finance, 2013, 5: 478-487.

[49] Srinivasan P, Ibrahim P. Forecasting stock market volatility of BSE-30 index using GARCH models. Asia Pacific Business Review, 2010, 6(3): 47-60. 